\title{
SIMULATING THE IMPACT OF BUILDING OCCUPANT PEER NETWORKS ON INTER- BUILDING ENERGY CONSUMPTION
}

\author{
Xiaoqi Xu \\ Columbia University \\ 264 S.W. Mudd Building, 500 West 120th Street \\ New York, NY 10027, USA
}

\author{
Anna Laura Pisello \\ University of Perugia \\ Strada S.Lucia Canetola s.n. \\ 06125 Perugia, ITALY
}

\author{
John E. Taylor \\ Virginia Tech \\ Charles E. Via, Jr. Department of Civil and Environmental Engineering \\ 113B Patton Hall \\ Blacksburg, VA24061, USA
}

\begin{abstract}
We developed an integrated inter-building physical and human network model to predict the energy conservation for an assumed urban residential block. We utilized an Artificial Neural Network to predict hourly energy consumption in both the first physical and second human stage. In the first stage, simulated data were exported from EnergyPlus, and the optimal scenario was found to consume $12.28 \%$ less energy than the base scenario. In the second stage, the human network closeness index was obtained from a residential experiment to represent occupants' network connections. We found that energy consumption can be further reduced up to $51.75 \%$. Finally, hour-by-hour energy consumption prediction under various levels of occupant networks was examined, and we found the block exhibits a potential of conserving $57.68 \%$ of the original energy consumption. An integrated understanding of physical and human network models on inter-building level energy consumption will enable us to better achieve energy efficiency objectives.
\end{abstract}

\section{INTRODUCTION}

There is strong political and societal will to reduce energy consumption in the built environment both domestically and abroad. The emphasis of much of this discussion, in particular where energy consumption reductions are included, focuses on the consumption of individual buildings. Yet this narrow focus on individual building consumption may be at the expense of potential savings that could result from examining energy consumption and conservation at the inter-building level. By examining groups of buildings, the full potential for energy reduction may be realized from a more harmonized interaction between individual buildings. These interactions can adopt the forms of optimized architectural and technical design, or coordinated electricity consumption, or even well connected occupant networks, all with the goal of better aggregate performance. At the inter-building level, two potential approaches have been considered very recently by researchers; a physical track which examines the potential impact on energy consumption when one building's impact on the energy consumption of another building is considered, and a human track which examines how building occupants may encourage energy conservation behaviors by other building occupants. Although we have seen recent research efforts to understand the aggregate ef- 


\section{Xu, Pisello, and Taylor}

fect of buildings on other buildings (Stromann-Andersen and Sattrup 2011) and building occupant networks (Peschiera, Taylor, and Siegel 2010), the approach to inter-building energy modeling that effectively integrates physical and human networks deserves attention.

Occupants' interpersonal connections can provide occupants the incentive to consume less energy, ostensibly due to a motivation that they want to keep up with their peers. This interpersonal effect on energy consumption has been observed and empirically supported in an experimental study (Peschiera, Taylor, and Siegel 2010). The researchers found that the peer network produced significant savings over the study period, indicating that a socially proximal norm provided with feedback could encourage reductions in energy consumption. Although the peer network is formed on a single building level, it can be generalized to the occupants' networks at the inter-building level, thus serving as a pivotal point between the two levels.

Artificial Neural Networks(ANN)are a recently developed approach that would be applicable to analyze the peer network effect described previously. ANN are computational tools which derive from biological neural networks. Analogous to a biological NN, an artificial NN can be trained of complex causal relationships among numerous factors. Because of this learning ability, ANN has been used in many fields for prediction, among which energy consumption is one area where ANN is highly suitable. ANN has the potential to model non-linear processes such as building energy loads and socio-economic factors (Aydinalpkoksal and Ugursal 2008), and it is more efficient than traditional simulation tools (Kalogirou 2000). Besides, ANN belong to the class of 'data-driven' instead of 'model-driven' approaches, thus little assumption and rationalization about relationships between variables is needed when exploring a new phenomenon. Because of its capability to model non-linear energy consumption under various socioeconomic backgrounds and its simplicity, we chose it as the simulation tool for this study.

With the motivation to integrate the physical and human networks to examine the energy consumption dynamics at an inter-building level, the sections below are organized as follows. Section 2 contains the description of the urban residential block in study, prior research on the physical modeling of building networks, and our ANN approach. In Section 3, the models and data are specified. The simulation results and analysis are presented in Section 4, followed by conclusion and contributions in Sections 5 and 6 respectively.

\section{BACKGROUND}

\subsection{Urban Residential Block Description}

We designed a typical American block of six residential single-family houses of three different sizes (Figure 1) located at Albany, New York. Every house has two floors: on the ground floor there are a kitchen, a living room, a connection area, and a bathroom, and on the upper floor there are two or three bedrooms, a bathroom and another connection area. The architectural properties of the buildings comprising the urban residential block were realistically designed with appropriate material physical properties for the floors, external walls, internal partition walls and roofs. Every indoor thermal zone was described by specific occupant schedules (Tronchin and Fabbri 2008) which associate appropriate internal gains values to human body functional activities, lighting, hot water needs, personal computer use, cooking appliances, etc.

\subsection{Physical Scenarios and Optimization}

The network energy efficiency assessment from a physical point of view is the starting point of this research. We examine an urban residential block to understand the impact of surrounding buildings on the energy consumption profile of an individual building. Because of the disparate modification strategies needed in summer and winter, and also the inverse inter-building effect from mutual shading of adjacent buildings on energy consumption in the two periods, only the summer period is chosen (May 1 to September 30) in this study to accurately evaluate the different scenarios' effects. And to fully take account 


\section{$X u$, Pisello, and Taylor}

of the inter-building effect within the group of buildings to serve our purpose of the study, we simulate the block as a whole, instead of a single house or a single room in a house.

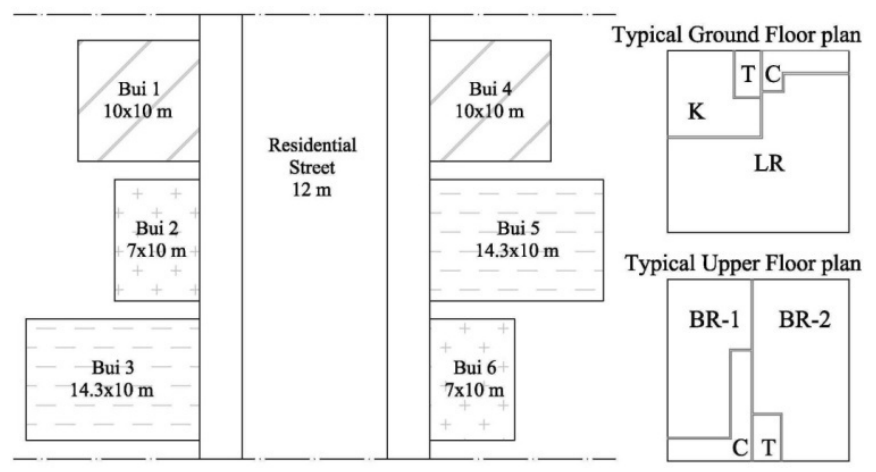

Figure 1: Urban residential block modeled (plan view).

Based on the base case inter-building simulation afforded by the building simulation program EnergyPlus (U.S. Department of Energy), other various envelope scenarios were studied, considering different envelope reflectance levels and positions, as well as shielding system visible-solar transmittance. Two groups of different scenarios were studied (Table 1) based on scenario 0 (the base case scenario): the first group $(1,2,3)$ focused on solar and visible transmittance levels of diffusive venetian blinds, while the second group $(4,5,6,7)$ described high reflectance $(90 \%)$ in different directions.

Table 1: Scenarios characterization.

\begin{tabular}{|l|l|l|}
\hline Scenarios & Solar and visible venetian blinds transmittance & Envelope superficial properties \\
\hline 0 & $100 \%$ (no blinds) & $\begin{array}{l}\text { Thermal Emissivity }=90 \% \\
\text { Solar-visible absorbance }=60 \%\end{array}$ \\
\hline 1 & $75 \%$ (with blinds) & Base case envelope reflectance \\
\hline 2 & $50 \%$ (with blinds) & Base case envelope reflectance \\
\hline 3 & $25 \%$ (with blinds) & Base case envelope reflectance \\
\hline 4 & $100 \%$ (no blinds) & High reflective facade \\
\hline 5 & $100 \%$ (no blinds) & High reflective lateral walls \\
\hline 6 & $100 \%$ (no blinds) & High reflective back walls \\
\hline 7 & $100 \%$ (no blinds) & High reflective envelope \\
\hline
\end{tabular}

From a physical point of view, we compared all the scenarios in terms of electricity demand. Summing the total energy consumption over the summer period in study, we found scenario 3 to be the most energy efficient scenario. Specifically, scenario 3 consumes $12.28 \%$ less energy than the base scenario 0 . It expresses the important role of the shielding system design during summer assessments. The convenient adjustment of venetian blinds avoids it from exerting negative impact to the thermal conditions in winter, ensuring scenario 3's benefit to the energy savings even if measured in the whole year period as well. With the above amount of energy savings achieved by optimizing physical features of the block, in this paper we will explore how the inter-building human networks can contribute to further energy conservation.

\subsection{Artificial Neural Network}

Researchers have applied ANN to forecast short term energy load (Kiartzis, Bakirtzis, and Petridis 1995; Khotanzad et al. 1997), for individual buildings or nationwide (Mihalakakou 2002; Aydinalp, Ugursal, and Fung 2002). ANNs have also been used to predict energy savings from building retrofits (Cohen and 


\section{$X u$, Pisello, and Taylor}

Krarti 1995) and conservation campaigns (Mahmoud and Alajmi 2010). Mahmoud and Alajmi (2010) used neural networks to assess the energy conservation induced by resident awareness resulting from energy campaigns, which is similar in nature with our study as both address the influences from awareness of occupants. Given the somewhat widespread use of ANN, we conclude it is suitable for our study.

However, in terms of incorporating socio-economic factors, existing efforts to model energy consumption adopt either a macro or micro level point of view. At the macro level, the socio-economic factors, such as population and average income, are taken into account in nationwide studies (Nizami 1995); while in micro level studies, details such as dwelling ownership and size of residence represent individual building information (Aydinalpkoksal and Ugursal 2008). To date, an intermediate view that examines energy consumption of a group of buildings that incorporates human networks as a socio-economic factor is lacking. This study aims to fill this gap by establishing an inter-building level network and incorporating the physical and human factors sequentially into the neural network. Detailed occupancy schedule and activities settings in EnergyPlus are socio-economic attributes in addition to the peer network effect that models how residents can influence each other's energy use. Taken together, these socio-economic factors make the physical-human integration examined more realistic. Given the optimized physical features of the cited buildings as networks study as a starting point, this paper explores how the personal network connections in the inter-building occupant network could affect the overall energy efficiency performance of the block.

\section{RESEARCH DESIGN AND METHODOLOGY}

\subsection{Models and Variables}

Two models are adopted in this study. The first model is applied to predict energy consumption in an optimal physical building network scenario. The second model is applied to predict further energy conservation under the added influence of the human networks that occupy the buildings. The two models are expressed in equations (1) and (2) respectively.

$$
\begin{aligned}
& E=f\left(T_{\text {op }}, T_{\text {out }}, \text { Solar, Occup }\right) \\
& E=f\left(T_{\text {op }}, T_{\text {out }}, \text { Solar, Occup, Network }\right)
\end{aligned}
$$

In equations (1) and (2), E represents energy consumption in kilowatts, which is the sum of cooling, hot water, lighting and other room electricity usage. Other than the term 'Network' in (2) which is derived from a residential experiment as a human network parameter, all other variables are exported as the simulated hourly data from the EnergyPlus program. The physical meaning of the variables are stated in Table2.

\subsection{Research Methodology}

The two models in 3.1 will be incorporated into two stages in this study respectively. The methodology flow chart of this study is illustrated in Figure 2. It can be divided into the individual building level and the inter-building level conceptually, as well as two stages operationally. The box with a dashed outline is information we draw from earlier studies.

\subsection{ANN Architecture}

Multi-layer feed-forward neural network is constructed for simulating the building networks. This neural network contains one input layer, one output layer, and two hidden layers each with ten hidden neurons in between. The transfer functions are chosen as log-sigmoid transfer function and linear transfer function for the hidden layer and output layer respectively, while the weights matrices $\mathrm{W}$ and bias vectors $\mathrm{b}$ are randomly generated. The structure of this neural network is shown in Figure 3, with all settings above inserted. 
$X u$, Pisello, and Taylor

Table 2: Description of variables

\begin{tabular}{|c|c|c|}
\hline \multicolumn{2}{|r|}{ Variable } & Description \\
\hline \multirow[t]{4}{*}{$\begin{array}{l}\text { Dependent } \\
\text { variables }\end{array}$} & $\begin{array}{l}\text { E: Energy } \\
\text { consumption }[\mathrm{kWh}]\end{array}$ & $\begin{array}{l}\text { Energy consumption }=\text { Cooling consumption }+ \text { Hot water } \\
\text { consumption }+ \text { Room electricity and Lighting consumption }\end{array}$ \\
\hline & $\begin{array}{l}\text { Cooling consumption } \\
{[\mathrm{kWh}]}\end{array}$ & $\begin{array}{l}\text { Energy that indoor environment needs to obtain and maintain } \\
\text { thermal target in summer. }\end{array}$ \\
\hline & $\begin{array}{l}\text { Hot water consumption } \\
{[\mathrm{kWh}]}\end{array}$ & $\begin{array}{l}\text { Energy that indoor environment needs to produce the } \\
\text { necessary hot water amount for human activities. }\end{array}$ \\
\hline & $\begin{array}{l}\text { Room electricity and } \\
\text { Lighting consumption } \\
\text { [kWh] }\end{array}$ & $\begin{array}{l}\text { Electricity that indoor environment needs to keep up all the } \\
\text { electric supplies for occupants' activities and for lighting } \\
\text { system. }\end{array}$ \\
\hline \multirow[t]{4}{*}{$\begin{array}{l}\text { Independent } \\
\text { variables }\end{array}$} & $\begin{array}{l}\mathrm{T}_{\mathrm{op}}: \text { Operative } \\
\text { temperature }[\mathrm{K}]\end{array}$ & $\begin{array}{l}\text { Indoor operative temperature. Average values within the free } \\
\text { running buildings. }\end{array}$ \\
\hline & $\begin{array}{l}\mathrm{T}_{\text {out }}: \text { Outdoor } \\
\text { Temperature }[\mathrm{K}]\end{array}$ & $\begin{array}{l}\text { Outdoor dry bulb temperature. Typical of the considered site } \\
\text { weather (Albany, NY). }\end{array}$ \\
\hline & Solar: Solar Gains [kWh] & $\begin{array}{l}\text { Short-wave solar radiation transmission through all external } \\
\text { windows, varying with time and weather. }\end{array}$ \\
\hline & $\begin{array}{l}\text { Occup: Occupants gains } \\
\text { [kWh] }\end{array}$ & $\begin{array}{l}\text { Sensible gain due to occupants related to activities } \\
\text { schedules. }\end{array}$ \\
\hline
\end{tabular}

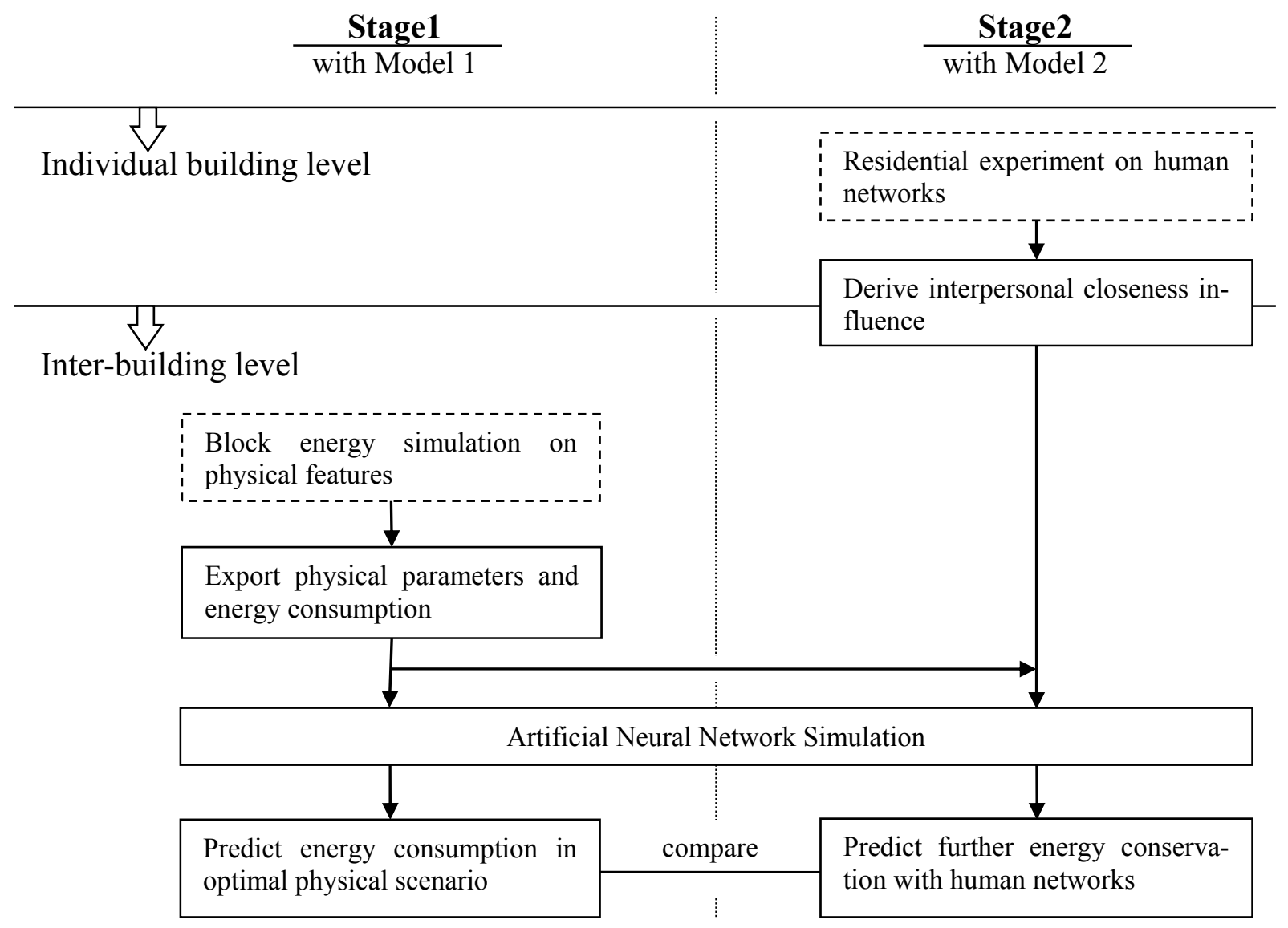

Figure 2: Research methodology flow chart 


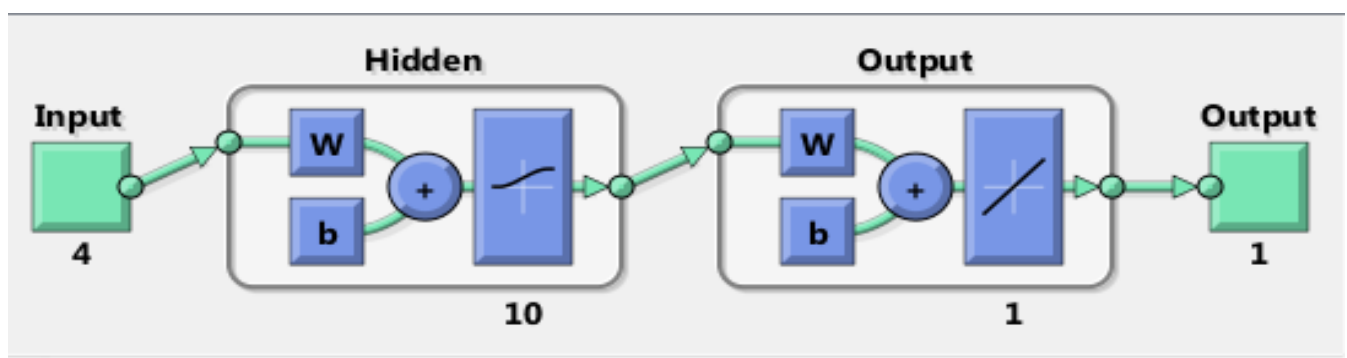

Figure 3: ANN architecture

The independent variables vector elements enter the network from the input layer, linking to the hidden layer. After adjusted by the weights matrix $\mathrm{W}$ and bias vector $\mathrm{b}$, initial outputs are directed from the neurons in the two hidden layers to the transfer function $\mathrm{f}$, and then reach the neurons in the output layer. Through the same process with different settings of $\mathrm{W}, \mathrm{b}$, and $\mathrm{f}$, outputs are obtained from the outlet of the output layer. Back-propagation is one of the most widely used training algorithms and is selected for use in our study (Rumelhart, Hint, and Williams 1986). Through a back-propagation algorithm with learning rate 0.1 , the neural network is trained and the error is minimized. In our case, error is the difference between the output and the target, which is the dependent variable E simulated in EnergyPlus.

\subsection{Data}

\subsubsection{Data in Model 1}

Data for model 1 are exported from EnergyPlus. These data are drawn from our previous work on physical building network energy consumption. Each of the variables is a vector of 3,672 hour-by-hour elements during the summer period, using May 1 to September 30typical weather measurements in Albany, New York.

\subsubsection{Additional Data for Model 2}

The 'Network' data in model 2 is derived from one of a series of experiments held in one Columbia urban multistory residential dormitory in New York City (Peschiera, Taylor, and Siegel 2010). The data for model 2 were imported from the data collected in this series of experiments from November 2009 to March 2010. Each resident classifies every other resident either as a stranger, acquaintance, friend, or close friend. Ratings of $0,1,2$, and 3 indicate the closeness of the relationship. Then summation of these numbers is taken for each resident throughout his/her network, and is applied as the closeness index of each resident's connection. After regressing energy reduction over the experiment period on this index, interpersonal closeness' influence on energy conservation can be expressed in percentage value. With significance level of less than $5 \%$, the conservation for an increment of 1 of the closeness index is found to reduce the energy consumption of the occupant by $3.45 \%$.

This closeness index serves as a bridge from individual building level network to inter-building level network analysis. We analogously compare each house to each other house in the block as each resident to each other in the urban residential building. Because the block consists of six houses, each house has five potential connections, with each rating from 0 to 3 as closeness. Altogether, each house's closeness index to the network ranges from 0 to 15 . Uniformly random numbers on $[0,15]$ are generated as 'Network,' and the variable ' $\mathrm{E}$ ' for model 2 to is adjusted by equation (3) from ' $\mathrm{E}$ ' in model 1 and serves as the updated target value.

$$
\mathrm{E}(\operatorname{model} 2)=\mathrm{E}(\operatorname{model} 1) *(1-\operatorname{network} * 3.45 \%)
$$




\subsubsection{Data Processing}

Data first go through a preprocessing procedure, such as normalization to $[0,1]$, to fit into the neural network dataset. The dataset is then divided into three subsets as training set, validation set, and test set, each contains $50 \%, 25 \%$, and $25 \%$ of the total set respectively. The training set is used for computing the gradient and updating the network weights and biases, and the data in the validation set is being monitored for its error to verify that the network does not overfit the data, while test set error is an indicator of generalization of the trained network.

\section{ANALYSIS}

\subsection{Prediction of Block Energy Consumption Under Optimal Physical Scenario}

This subsection displays prediction results of stage 1, where the variables of model 1 under the optimal scenario(s3) are used to train the neural network. The validation result of the entire dataset is shown in Figure 4, and the energy consumption for a typical week in summer (August $19^{\text {th }}$ to August $25^{\text {th }}$ ) is contained in Figure 5.

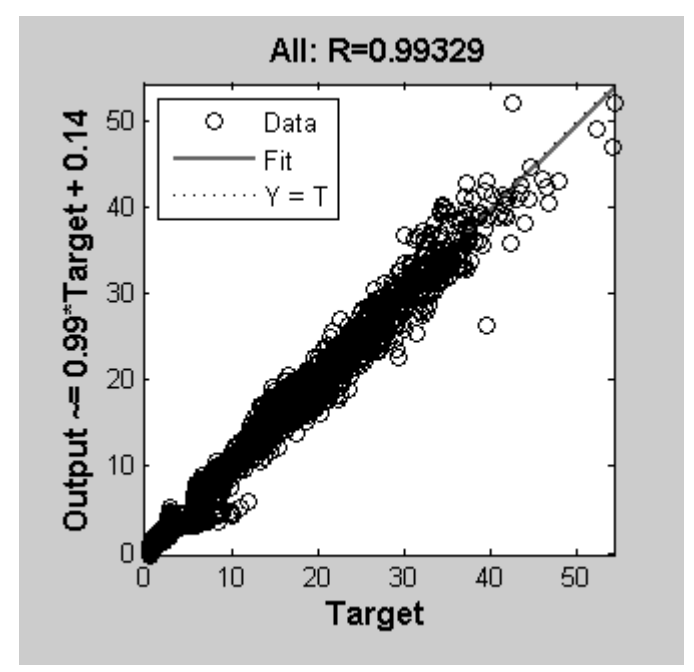

Figure 4: Validation of model 1

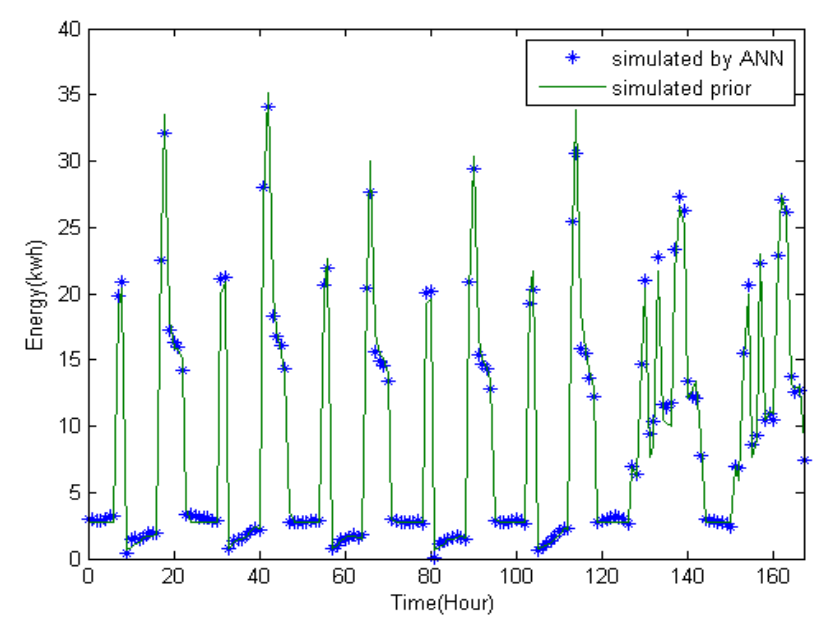

Figure 5: Energy consumption under s3

Both figures support the validity of the simulation results of the artificial neural network. In Figure 4, simulated output points are placed against their targets, i.e., prior simulated results from EnergyPlus. The entire dataset approximately fall along a 45 degree line, verifying the proximity of the output and target values. Altogether, the correlation coefficient $\mathrm{R}$ between the two is high at 0.99329 . In Figure 5, the majority of the simulated energy consumption points coincide with the prior simulated measurements of energy consumption. The percentage difference between the predicted values and previously simulated values is $0.04 \%$, but it will vary for each simulation due to the randomly generated weights matrix and bias vector. The first five days of the week have different period consumption pattern with the last two days, which is because of disparate occupant schedule settings for weekdays and weekends.

\subsection{Prediction of Further Energy Conservation Under the Peer Influence of Human Networks}

As changing physical features results in optimized energy efficiency shown in subsection 4.1, introducing interpersonal closeness index into the network in stage 2 will lead to further energy conservation. The validation result of the entire dataset is shown in Figure 6, and energy consumption under four levels of human network closeness settings during the same week is shown in Figure 7. 


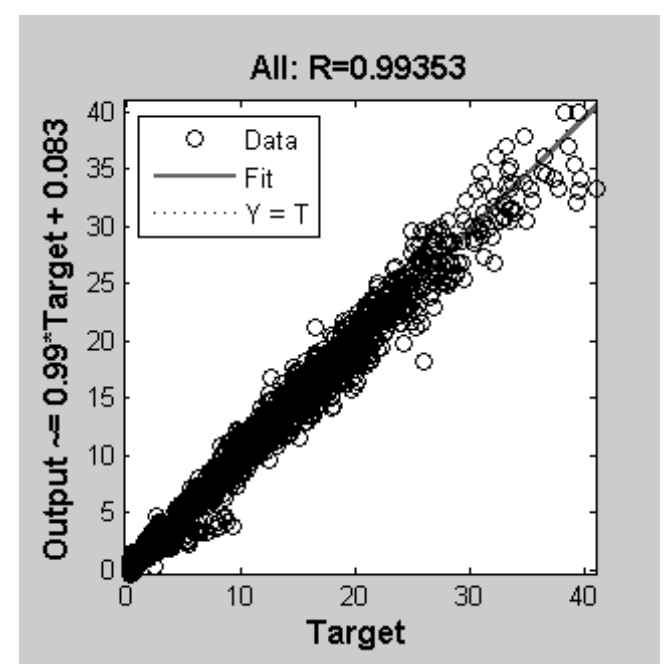

Figure 6: Validation of model 2

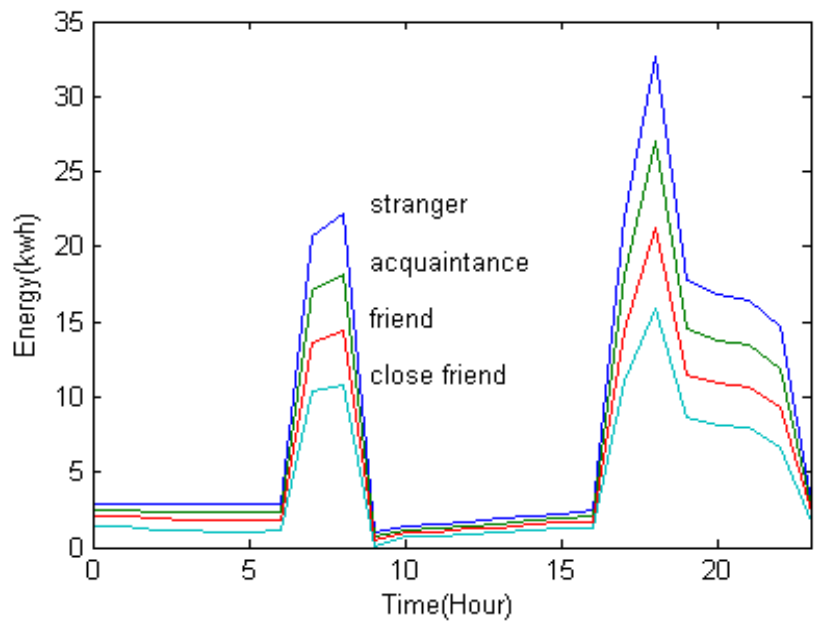

Figure 7: Energy consumption under human networks

Supported by a correlation coefficient of 0.99353 , the neural network incorporating human closeness index is well trained and provides strong predictive capability. Figure 7 shows energy consumption of the block for a typical day with the following human network settings:

- each family is 'stranger' with the other five families, thus the closeness index for each family is 0 ;

- each family is 'acquaintance' with the other five families, then the closeness index for each family is 5 ;

- each family is 'friend' with the other five families, then the closeness index for each family is 10 ; and

- each family is 'close friend' with the other five families, then the closeness index for each family is 15 .

An increment from each level of interpersonal networks to the next closer level will lead to an energy conservation of approximately $3.45 \% * 5=17.25 \%$, and a maximum of $3 * 17.25 \%=51.75 \%$ energy savings are achieved when all families are close friends with each other, both of which are consistent with the simulated result from ANN as shown in Figure 7.There are numerous intermediate closeness levels between the all-stranger and all-close-friend levels, hence actual energy use reductions would likely fall somewhere within this range. Values for differing levels could also be derived from applying the trained ANN. However, only the four unified network constructs are displayed here for simplicity. The shape of each line has a trough between $9 \mathrm{am}$ to $4 \mathrm{pm}$, which is results from the occupant schedule setting that people are generally out of their homes during the day on weekdays.

To integrate the physical and human stages, recalling scenario 3 consumes $12.28 \%$ less energy than the base scenario 0 , the block shows a potential of consuming $1-(1-12.28 \%) *(1-51.75 \%)=57.68 \%$ less energy than the baseline block scenario in which no residents influence each other's energy consumption.

\section{CONCLUSION}

In this paper we drew from earlier research that modeled a physical building network of a typical urban residential block of homes and that examined the role of peer networks on energy consumption in an urban residential building. We then applied artificial neural network methods in two stages to examine the impact of integrating buildings as networks and human occupant networks on energy consumption. In the first physical stage, an optimized scenario was selected in which blinds transmittance was minimized during summer. In this case we found the energy consumption to be $12.28 \%$ less than the normal base scenario. Using hourly data exported from EnergyPlus with the physical settings of this scenario, we then applied artificial neural network methods to predict inter-building level total energy consumption under 


\section{Xu, Pisello, and Taylor}

the optimized physical scenario for best energy efficiency. To include the inter-building occupant network influence on individual energy consumption decisions, we incorporated a closeness index derived from a residential experiment to predict further energy conservation under the influence of human networks in the second stage. Hourly energy consumption series were obtained for multiple assumed occupant network closeness settings, with the maximum of 51.75\% energy savings when all families are close friends with each other. Integrating the physical and human stages, the block shows a potential of consuming $57.68 \%$ less energy than the baseline block scenario in which no residents influence each other's energy consumption. Both ANN models achieve as high as 0.99 correlation coefficients for the entire dataset, statistically supporting the above quantitative conclusion.

\section{CONTRIBUTIONS AND IMPACTS}

This study answers the question of how occupant network closeness could affect the overall energy performance at the inter-building level for an optimized physical building network design. Although the optimized human network design where occupants for all neighboring buildings in an urban residential block are close friends is unlikely, it is important to note the substantially larger potential impact of an optimized human network over an optimized physical network of buildings. Future research should empirically examine whether and at what point a synergistic effect between physical networks of buildings and human networks occupying those buildings may occur leading to more optimal energy conservation outcomes. Occupant network influence may potentially be harnessed by urban planners to promote residential energy conservation in combination with physical designs by, for example, including more shared spaces where neighboring occupants may interact or installation of shared energy monitoring systems and incentives. The potential impact of inter-building level energy management is quantitatively illustrated by these results. Adopting a network perspective of urban residential buildings and the networks of individuals that occupy them has the potential to result in better energy efficiency and reduction in greenhouse gas emissions.

\section{REFERENCES}

Aydinalp, M., V. I.Ugursal, and A.S. Fung. 2002. "Modeling of the Appliance, Lighting, and SpaceCooling Energy Consumptions in the Residential Sector Using Neural Networks." Applied Energy 71: 87-110.

Aydinalpkoksal, M., and V. I.Ugursal. 2008. "Comparison of Neural Network, Conditional Demand Analysis, and Engineering Approaches for Modeling End-Use Energy Consumption in the Residential Sector." Applied Energy 85(4):271-296. doi:10.1016/j.apenergy.2006.09.012. Accessed July 15, 2011. http://linkinghub.elsevier.com/retrieve/pii/S030626190600136X.

Cohen, D.A., and M.Krarti. 1995. "A Neural Network Modelling Approach Applied to Energy Conservation Retrofits." Proceedings of the Building Simulation Fourth International Conference, 423-430.

Kalogirou, S.A. 2000. "Artificial Neural Networks for the Prediction of the Energy Consumption of a Passive Solar Building." Energy 25: 479-491.

Khotanzad, A., R. Afkhami-Rohani, T.L. Lu, A. Abaye, M. Davis, and D.J. Maratukulam. 1997. "ANNSTLF-A Neural-Network-Based Electric Load Forecasting System." IEEE Transactions on Neural Networks 8(4): 835-846. Accessed July $15 \quad 2011$. http://ieeexplore.ieee.org/xpls/abs_all.jsp?arnumber=595881.

Kiartzis, S. J., A. G. Bakirtzis, and V. Petridis. 1995. "Short-Term Load Forecasting Using Neural Networks." Electric Power Systems Research 33(1):1-6.

Mahmoud, M. A., and A. F. Alajmi. 2010. "Quantitative Assessment of Energy Conservation Due to Public Awareness Campaigns Using Neural Networks." Applied Energy 87(1, January): 220-228.

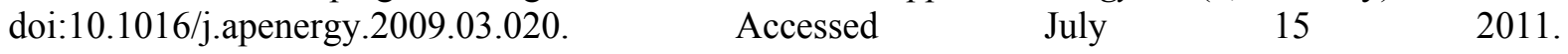
http://linkinghub.elsevier.com/retrieve/pii/S0306261909000877. 
Mihalakakou, G. 2002. "On the Energy Consumption in Residential Buildings." Energy and Buildings 34(7, August): 727-736. doi:10.1016/S0378-7788(01)00137-2. Accessed July 15, 2011. http://linkinghub.elsevier.com/retrieve/pii/S0378778801001372.

Nizami, S. S. and A. K. Javeed. 1995. "Forecasting Electric Energy Consumption Using Neural Networks." Energy policy 23(12):1097-1104.

Peschiera, G., J. E. Taylor, and J. A. Siegel. 2010. "Response-Relapse Patterns of Building Occupant Electricity Consumption Following Exposure to Personal, Contextualized and Occupant Peer Network Utilization Data." Energy and Buildings 42(8, August): 1329-1336. doi:10.1016/j.enbuild.2010.03.001. Accessed July 2011. http://linkinghub.elsevier.com/retrieve/pii/S0378778810000691.

Rumelhart, D. E., G. E. Hint, and R. J. Williams. 1986. "Learning Internal Representations Error Propagation." Nature 323(9):533-536.

Stromann-Andersen, J., and P. A. Sattrup. 2011. "The urban canyon and building energy use: Urban density versus daylight and passive solar gains." Energy and Buildings 43 (8): 2011-2020. doi:10.1016/j.enbuild.2011.04.007. Accessed July 2011. http://linkinghub.elsevier.com/retrieve/pii/S0378778811001605.

Tronchin, L., and K. Fabbri. 2008. "Energy Performance Building Evaluation in Mediterranean Countries: Comparison between Software Simulations and Operating Rating Simulation." Energy and Buildings 40(7): 1176-1187. doi:10.1016/j.enbuild.2007.10.012. Accessed July 14, 2011. http://linkinghub.elsevier.com/retrieve/pii/S0378778807002447.

U.S. Department of Energy. 2011. "Energy Efficiency and Renewable Energy, Building Technologies Program: EnergyPlus.” Accessed July 15. http://apps1.eere.energy.gov/buildings/energyplus/.

\section{AUTHOR BIOGRAPHIES}

XIAOQI XU is a MS-Ph.D. student in the department of Civil Engineering and Engineering Mechanics at Columbia University. She received her Bachelor of Science in Construction Management from Tsinghua University, China, and a dual Bachelor of Economics from the China Center for Economic Research at Peking University, China. Her research in the Project Network Dynamics Lab at Columbia University currently focuses on building networks simulation. She expands it to the integration and interaction of physical environment and occupant networks to improve aggregate building energy efficiency. She is also interested in involving economics and statistics related theory and approach to her research in future. Her email isxx2145@columbia.edu.

ANNA LAURA PISELLO is a PhD student in Energy Engineering at University of Perugia, Italy, and currently a visiting scholar at Columbia University, New York. She is a constituent member of IBPSAItaly (International Building Performance Simulation Association). Her research is focused on thermal performance of building, and networks of buildings, through dynamic simulation and experimental monitoring. Her email address is pisello@crbnet.it.

JOHN E. TAYLOR is an Associate Professor in the Charles E. Via, Jr. Department of Civil and Environmental Engineering at Virginia Tech. He received his Ph.D. from Stanford University in 2006. He is Director of the Civil Engineering Network Dynamics Lab at Virginia Tech and specializes in the investigation of network dynamics of industrial and societal importance. His current research focuses on three key network dynamics; (1) achieving sustained energy conservation in the built environment by coupling energy use and energy conservation practices with building occupant networks, (2) the trending increase in global outsourcing of complex engineering services, and (3) examining the impact of integrated information systems on project networks and the associated virtualization of the engineering workforce. His email is jet@vt.edu. 